\title{
A double dose of double effect
}

\author{
C E Kendall St Peter's Hospice, Bristol
}

\begin{abstract}
This paper presents a clinically orientated illustration of the doctrine of double effect. The case of an elderly gentleman with advanced cancer is discussed, with particular emphasis on two dilemmas encountered during the terminal phase of his illness. The author describes how the doctrine of double effect was applied to help the team make some complex management decisions.
\end{abstract}

(Fournal of Medical Ethics 2000;26:204-206)

Keywords: Doctrine of double effect; competence; ethics; beneficence

\section{Introduction}

A fundamental basic principle of ethics in medicine is that of beneficence to all. The physician is required at all times to seek the course of action which is in the best interests of the patient. Equally he or she must strive to do no harm to his or her patients; this is known as the principle of non-maleficence. The physician is responsible for the life of the patient whilst under his care. These principles date back to the Hippocratic Oath in Ancient Greece but are just as valid today as when they were first written.

In the care of patients with incurable disease, ethical considerations form an integral part of their management and some challenging situations call for consideration of the doctrine of double effect. The physician's intention, as stated, must be to cause good overall, and any treatments are offered only after calculation of the risk versus benefit to that patient. Sometimes the relief of suffering, the intended good effect, also has a potential bad effect which is foreseen but not the primary intention, hence "double effect". ${ }^{2}$

The application of the doctrine of double effect in end-of-life decisions, particularly concerning opioid use for relief of suffering can be complex and controversial. Whilst the doctrine has clear criteria which must be met for it to be applied, it is arguable that it is misinterpreted in some of these situations.

The doctrine of double effect states that a harmful effect of treatment, even resulting in death, is permissible if it is not intended and occurs as a side effect of a beneficial action. ${ }^{3}$

The criteria which must be met for it to apply are:

The intended effect must be a good one.

The harmful effect must be foreseen but not intended.

The harmful effect must not be a way of producing the good effect.

The good effect must on balance outweigh the harmful effect.

The case recounted illustrates the management of two clinical dilemmas during the care of a gentleman with advanced cancer which are clarified by application of the doctrine of double effect. The first was whether to use a drug that had the potential to cause a life-threatening bleed. The second was whether to remove an epidural catheter (a thin tube which is inserted into the back in order to deliver drugs into the space around the spinal cord), the site of which had become infected.

\section{Case history}

DM was a 78-year-old male with advanced carcinoma of the prostate that had spread to his bones and bone marrow. He was admitted to the hospice for symptom control of severe bone pain in his back.

The involvement of his bone marrow led to a very low number of platelets in his blood, and this meant his blood did not clot easily, putting him at risk of bleeding. This risk was compounded by the fact that he was taking diclofenac (a non-steroidal anti-inflammatory drug which is often helpful in the control of bony pain). Diclofenac interacts with platelets thus further reducing the ability of the blood to clot and increasing the risk of a lifethreatening bleed. We stopped the diclofenac and over the following days his pain increased significantly but did not come under control despite our trying a range of strong pain-killing drugs.

So, the first dilemma was as follows: a man who was near the end of his life, was in severe pain. He had taken diclofenac prior to admission with good 
effect for bony pain. However, the use of diclofenac was contra-indicated because of the high risk of bleeding which could potentially hasten his death.

\section{Should the diclofenac be restarted?}

By application of the doctrine of double effect one could argue it should be restarted because:

The intention was to control the severe pain in his back.

The potential hazard of using the diclofenac had been foreseen but was certainly not the primary aim of it's use.

The good effect of easing his pain outweighed the risk of hastening his death due to side effects of the medication.

In the first situation the patient was autonomous. $\mathrm{He}$ and his wife were fully involved in the discussions and understood the risks. He opted to try the diclofenac in the hope of improving his pain. Indeed, his pain did improve and he only had minor bleeding problems which were easily managed.

Later in his admission his pain escalated once more to such an extent that the nurses were unable to move him in his bed. This increase in pain was difficult to manage despite alterations to his oral medication, so an epidural was used with great success. After many weeks of imperfect pain control this was a great relief not only for him but for all involved in his care. However, this was short-lived because a week or so later the epidural site became infected.

The second dilemma was as follows:

Here was a man very near the end of his life who was dying anyway, deteriorating and the site of the epidural catheter was not a factor in this. For the first time in many weeks he was well paincontrolled using the epidural. The options for achieving good pain control without the epidural were very limited as he had reacted badly to all the strong painkillers that had been previously tried. The protocol stated that the epidural catheter should be removed, since leaving it in could result in serious infection of his brain (meningitis) which could hasten his death. At this stage he was not competent to be part of any decision.

Should the epidural catheter be removed? By application of the doctrine of double effect one could argue it should not be removed because:

He was close to death from the effects of his advanced malignancy and the intention was to maintain the good quality of pain relief afforded by the epidural.
It had been foreseen that he might develop a serious complication from the infected site by leaving it in place and that this was very likely to hasten his death. However, there was no available evidence of the exact risk of this because in "healthier" patients that risk is never taken.

It was felt that even if he did develop meningitis and this shortened his life, it was still preferable for him to be pain-free with the epidural in place than to have his pain out of control once more. Moreover, the risk of him developing meningitis could not be quantified.

The epidural was left in place and he died peacefully 48 hours later, with no apparent evidence of intracranial infection.

\section{Case reflection}

In both situations the doctrine of double effect was a useful framework around which to make the decisions. In the first situation the patient was competent and able to indicate his choice of treatment, once he was in possession of the risk-benefit information. In the second situation he was not competent so in order to act in his best interests the risk-benefit of our inaction was weighed up on his behalf, using the principles of the doctrine.

The decisions made for and on behalf of this gentleman took a lot of careful consideration. The team were aware of the potential consequences of their recommendations but central to them were the INTENT with which they were made. This is key to the application of the doctrine.

However, it can also mean the doctrine is open to abuse as it depends heavily on the integrity and honesty of the person applying it, and intent is very difficult to prove.

Part of the aim of this paper is to offer clinical dilemmas for debate where the reader can decide whether the doctrine of double effect supports the clinical decisions made in the management of this gentleman. The team concerned felt it did.

C E Kendall, MRCGP, DCH, DRCOG, is Senior House Officer in Palliative Medicine, St Peter's Hospice, Bristol. Address for correspondence: St Peter's Hospice, St Agnes Avenue, Knowle, Bristol BS4 2DU.

\section{References}

1 Wilkinson J. Ethical issues in palliative care. In: Doyle D, Hanks J, McDonald N, eds. Oxford textbook of palliative medicine [2nd ed]. Oxford: Oxford Medical Publications, 1997: ch 3.

2 Randall F, Downie R. Palliative care ethics: a good companion. Oxford: Oxford Medical Publications, 1996: 71-3.

3 Gillon R. The principle of double effect and medical ethics. British Medical fournal 1986;292:259-61. 